\title{
Comparison of five bacterial strains producing siderophores with ability to chelate iron under alkaline conditions
}

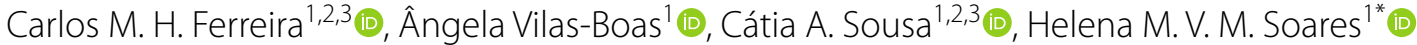 \\ and Eduardo V. Soares ${ }^{2,3^{*}}$ (B)
}

\begin{abstract}
Iron deficiency is one of the main causes of chlorosis in plants, which leads to losses in field crops quality and yield. The use of synthetic chelates to prevent or correct iron-deficiency is not satisfactory mainly due to their poor biodegradability. The present work aimed to search suitable microorganisms to produce alternative, environment-friendly iron-chelating agents (siderophores). For this purpose, the performance of five bacteria (Azotobacter vinelandii, Bacillus megaterium, Bacillus subtilis, Pantoea allii and Rhizobium radiobacter) was evaluated, regarding siderophore production kinetics, level of siderophore production (determined by chrome azurol S, CAS method), type of siderophore produced (using Arnow and Csaky's tests) and iron-chelating capacity at pH 9.0. All bacteria were in stationary phase at $24 \mathrm{~h}$, except $A$. vinelandii (at $72 \mathrm{~h}$ ) and produced the maximum siderophore amount $\left(80-140 \mu \mathrm{mol} \mathrm{L}^{-1}\right.$ ) between 24 and $48 \mathrm{~h}$, with the exception of A. vinelandii (at $72 \mathrm{~h}$ ). The analysis of culture filtrates revealed the presence of catechol-type siderophores for B. subtilis and R. radiobacter and hydroxamate-type siderophores for B. megaterium and P. allii. In the case of $A$. vinelandii, both siderophore-types (catechol and hydroxamates) were detected. The highest iron-chelating capacity, at pH 9.0, was obtained by B. megaterium followed by B. subtilis and A. vinelandii. Therefore, these three bacteria strains are the most promising bacteria for siderophore production and chlorosis correction under alkaline conditions.
\end{abstract}

Keywords: Catechol and hydroxamates-type siderophores, Environment-friendly chelating agents, Iron chelation under alkaline conditions, Microorganisms, Siderophore production

\section{Introduction}

Iron is an essential nutrient for plant development together with macronutrients (Barker and Stratton 2015). Although not present in chlorophyll, iron is necessary for its synthesis and for the functioning of the photosynthetic apparatus (Broadley et al. 2012). The lack of iron in plants leads to develop a symptomatic array, named chlorosis. It is characterized by the development of yellow

\footnotetext{
*Correspondence: hsoares@fe.up.pt; evs@isep.ipp.pt

${ }^{1}$ REQUIMTE/LAQV, Departamento de Engenharia Química, Faculdade de Engenharia, Universidade do Porto, rua Dr. Roberto Frias, 4200-465 Porto, Portugal

${ }^{2}$ Bioengineering Laboratory-CIETI, Chemical Engineering Department, ISEP-School of Engineering of Polytechnic Institute of Porto, rua Dr António Bernardino de Almeida, 431, 4249-015 Porto, Portugal Full list of author information is available at the end of the article
}

young leaves as a result of insufficient iron for the efficient chlorophyll production (Lucena 2000). Chlorotic plants will under develop, produce less biomass and yield less flowers and fruits, or, in ultimate case, lead to complete crop failure (Guerinot and Yi 1994). Some crops known to be susceptible to iron chlorosis are peach, kiwifruit, citrus and pear (Lucena 2003), although some other valuable crops have also been described to suffer from chlorosis, such as rice (Yoshida et al. 1996), soybean (Froechlich and Fehr 1981), tomato (Chaney et al. 2008) and pea (Kabir et al. 2016).

The low bioavailability of iron is due to its chemical nature and its low solubility and dissolution kinetics, which limits the absorption of iron by plants, especially in calcareous soils. Since it is estimated that calcareous soils 
cover about $30 \%$ of world's cultivated soils (Barker and Stratton 2015; Cianzio et al. 2006), this data underlines the importance of iron deficiency as a major global agricultural problem. To surpass the problem of chlorosis, organic chelating agents have been used, such as aminopolycarboxylic acids (APCAs), to correct iron deficiency. Although, these compounds are strong chelating agents, usually they are not biodegradable. Thus, their persistence and consequent accumulation in aquatic systems is becoming a matter of great concern, as they can mobilize toxic metals (Bucheli-Witschel and Egli 2001). Therefore, the search for environmental-friendly and suitable iron chelators, with specific properties to be used, as iron fertilizers, has become a great challenge. Among a great number of compounds considered, siderophores are an interesting object of study since they are effective iron chelating compounds and have the advantage of being more biodegradable than synthetic APCAs (Fazary et al. 2016a, b).

Siderophores are low weight molecules (between 500 and 1500 dalton) with great affinity and selectivity to bind and complex Fe(III). They are produced by microorganisms, as well as by some gramineous plant, as part of a strategy to obtain iron from the environment because of the low amount of iron bioavailable (Hider and Kong 2010). This particular trait has drawn the attention of many researchers in recent years. For instance, some studies have been conducted in search on new siderophore producing species. Grobelak and Hiller (2017) have conducted a screening of bacteria (Bacillus spp. and Pseudomonas spp.) isolated from plant's roots for catechol and hydroxamate producing bacteria. The positive effects of siderophore producing bacteria have been recently studied by different authors (Liu et al. 2017; Sabaté et al. 2017; Trifi et al. 2017).

Considering that iron deficiency is a yield-limiting factor with major implications for crop management, the production of siderophores compounds is an important challenge. In recent works (Ferreira et al. 2019a; Martins et al. 2018), it was shown that synthetic compounds containing catecholate and hydroxamate groups are potential iron chelators for iron nutrition in plants. However, due to the high structural complexity of siderophores, its production by chemical synthesis involves several low yield steps, which limits the feasibility of their use for agriculture purposes, as it is illustrated in the synthesis of azotochelin (Leydier et al. 2008; Martins et al. 2018). One alternative is the microbial (biotechnological) production of siderophores.

The present work aimed to seek for bacteria that can be further used in the production of environment-friendly suitable iron chelators. These compounds should be produced at low cost, in order to be used in agriculture as iron fertilizers. For this purpose, five bacterial strains of different genera were chosen taking into account the following criteria: (i) ability to produce catecholates or hydroxamates siderophores, as these compounds display the highest affinity to iron (Hider and Kong 2010); (ii) absence of pathogenicity to humans, i.e., belonging to risk 1 (U.S. Department of Health and Human Services et al. 2009). These strains were evaluated in order to select those which seem to be the most promising siderophore producers, considering the following parameters: efficiency of iron-complexing capacity at $\mathrm{pH}$ 9.0, amount of siderophore produced, type of siderophore, speed of siderophore production, growth and handling of the strain (growth, nutritional requirements, culture medium composition and easiness of biomass separation from the culture medium).

\section{Materials and methods}

\section{Microorganisms, media and culture conditions}

As a result of a literature survey previously performed for siderophore producer bacterial strains (Ferreira et al. $2019 \mathrm{~b})$ and taking into to account the selection criteria presented above, the following microorganisms were chosen to be used in the present work: Azotobacter vinelandii Deutsche Sammlung von Mikroorganismen und Zellkulturen (DSM) 2289; Bacillus megaterium American Type Culture Collection (ATCC) 19213; Bacillus subtilis DSM 10; Pantoea allii DSM 25133; and Rhizobium radiobacter DSM 30205. The original strains were obtained from DSM, Germany, or ATCC, U.S.A. All these bacteria belong to Risk 1 group, according to the U.S. Department of Health and Human Services, Centers for Disease Control, and National Institutes of Health (2009).

The microorganisms were maintained in minimal medium (MM) agar, except $A$. vinelandii, which was maintained in Burk's medium (BM) agar, at $4{ }^{\circ} \mathrm{C}$. MM agar contained per litre: $10 \mathrm{~g}$ glucose, $1.47 \mathrm{~g}$ glutamic acid, $3.0 \mathrm{~g}$ potassium hydrogenophosphate $\left(\mathrm{K}_{2} \mathrm{HPO}_{4}\right)$, $1.0 \mathrm{~g}$ potassium dihydrogenophosphate $\left(\mathrm{KH}_{2} \mathrm{PO}_{4}\right), 0.5 \mathrm{~g}$ ammonium chloride $\left(\mathrm{NH}_{4} \mathrm{Cl}\right), 0.1 \mathrm{~g}$ ammonium nitrate $\left(\mathrm{NH}_{4} \mathrm{NO}_{3}\right), 0.1 \mathrm{~g}$ sodium sulphate $\left(\mathrm{Na}_{2} \mathrm{SO}_{4}\right), 10 \mathrm{mg}$ magnesium sulphate heptahydrate $\left(\mathrm{MgSO}_{4} \cdot 7 \mathrm{H}_{2} \mathrm{O}\right)$, $1 \mathrm{mg}$ magnesium sulphate tetrahydrate $\left(\mathrm{MnSO}_{4} \cdot 4 \mathrm{H}_{2} \mathrm{O}\right)$, $0.5 \mathrm{mg}$ calcium chloride $\left(\mathrm{CaCl}_{2}\right)$ and $20 \mathrm{~g}$ agar. $\mathrm{BM}$ agar was prepared as previously described (HiMedia Laboratories 2015) replacing sucrose by glucose; the medium contained per litre: $10 \mathrm{~g}$ glucose, $0.8 \mathrm{~g} \mathrm{~K}_{2} \mathrm{HPO}_{4}, 0.2 \mathrm{~g}$ $\mathrm{KH}_{2} \mathrm{PO}_{4}, 0.20 \mathrm{~g} \mathrm{MgSO}_{4} \cdot 7 \mathrm{H}_{2} \mathrm{O}, 0.253 \mathrm{mg}$ sodium molybdate, $0.13 \mathrm{~g}$ calcium sulphate and $20 \mathrm{~g}$ agar. The final $\mathrm{pH}$ of the media was set to $7.0 \pm 0.1$. For iron-replete media, $29 \mathrm{mg}$ of iron(III) chloride $\left(\mathrm{FeCl}_{3}\right)$ was also added.

All reagents used were obtained from Merck (Darmstadt, Germany), Panreac (Barcelona, Spain), 
Sigma-Aldrich (St. Louis, Missouri, EUA) or BD Difco (Waltham, Massachusetts, EUA). Inorganic chemicals were pro-analysis grade while organic chemicals were $\mathrm{Ph}$. Eur. grade.

In order to avoid iron contamination (on iron-deficient-cultures), all glassware was soaked in $10 \%$ nitric acid, overnight and, subsequently, washed with deionized water prior to use.

All pre-starter cultures, with exception of $A$. vinelandii, were prepared by inoculating the bacteria in $20 \mathrm{~mL}$ of iron-replete MM broth in $100 \mathrm{~mL}$ Erlenmeyer flasks. Cells were incubated at $30{ }^{\circ} \mathrm{C}$, for $8 \mathrm{~h}$, in an orbital shaker at $150 \mathrm{rpm}$. Starter cultures were prepared by inoculating $40 \mathrm{~mL}$ of iron-replete MM broth, in $100 \mathrm{~mL}$ Erlenmeyer flasks, with an appropriate volume of the pre-starter cultures, and then incubated overnight to an $\mathrm{OD}_{600} \approx 2.0$, under the same conditions described for the pre-starter cultures. Cells, in exponential phase of growth, were harvested by centrifugation $(3000 \times g, 10$ to $30 \mathrm{~min}$ ), rinsed and suspended in iron-deficient media. Next, cultures were obtained by inoculating the cells in $400 \mathrm{~mL}$ of iron-deficient $\mathrm{MM}$ broth (initial $\mathrm{OD}_{600} \approx 0.1$ ), in $1 \mathrm{~L}$ Erlenmeyer flasks. Cells were incubated under the same conditions as described above. For A. vinelandii, there were some differences in the protocol: BM broth was used instead of MM broth and only a starter culture was grown, for $24 \mathrm{~h}$, due to the slower growth rate of the bacterium.

\section{Determination of siderophore production}

Due to its easiness and ability for a high and sensitive detection of siderophores (Schwyn and Neilands 1987), the chrome azurol S (CAS) method was used (Alexander and Zuberer 1991) in the estimation of the bacterial siderophore production. Therefore, samples were taken and cells were pelleted by centrifugation $(3000 \times g, 10$ to $30 \mathrm{~min}$ ). The supernatant was carefully removed and, subsequently, filtered through a $0.45 \mu \mathrm{m}$ pore size filter and immediately stored at $-20{ }^{\circ} \mathrm{C}$ until siderophore determination.

CAS method consists in mixing $1.0 \mathrm{~mL}$ of filtrate, properly diluted with deionized water, with $1 \mathrm{~mL}$ of CAS assay solution, prepared as described by Alexander and Zuberer (1991). One reference solution was also prepared by mixing $1.0 \mathrm{~mL}$ of CAS solution with $1.0 \mathrm{~mL}$ of deionized water. A zero-absorbance solution was also prepared by mixing $1.0 \mathrm{~mL}$ of CAS solution with $1.0 \mathrm{~mL}$ of $100 \mu \mathrm{mol} \mathrm{L}^{-1}$ desferrioxamine mesylate salt (desferal). The solutions were left to reach chemical equilibrium at room temperature in the dark for $24 \mathrm{~h}$. Next, absorbance was read at $630 \mathrm{~nm}$. A calibration curve was performed by plotting the ratio $\mathrm{A} / \mathrm{A}_{\text {ref }}$ versus the concentration of desferal; where, A is the standard solution absorbance at $630 \mathrm{~nm}$ and $\mathrm{A}_{\text {ref }}$ stands for absorbance of the reference at $630 \mathrm{~nm}$. Siderophore production is expressed as $\mu \mathrm{mol} \mathrm{L}{ }^{-1}$ desferal equivalent. For each culture, samples were read in triplicate and repeated independently at least two times (that is, two independent cultures read in triplicate).

\section{Siderophore qualification}

The type of siderophore present in each bacterial medium was characterized using Arnow's and the Csaky's methods for catecholates and hydroxamates, respectively (Payne 1994).

Arnow method is based on the reaction between catechol and nitrite-molybdate reagent, in acidic conditions, originating a yellow colour. The colour changes to an intense orange-red in alkaline conditions. For this purpose, $1.0 \mathrm{~mL}$ of culture filtrate was combined with $1.0 \mathrm{~mL}$ of $\mathrm{HCl} 0.5 \mathrm{~mol} \mathrm{~L}^{-1}$. Subsequently, $1.0 \mathrm{~mL}$ of nitrite-molybdate reagent was added and then $1.0 \mathrm{~mL}$ of $\mathrm{NaOH} 1.0 \mathrm{~mol} \mathrm{~L}^{-1}$. The assay was incubated at room temperature, for approximately $5 \mathrm{~min}$, to allow full colour development. As blank, $1.0 \mathrm{~mL}$ of deionised water was used. Nitrite-molybdate reagent was prepared by dissolving $10 \mathrm{~g}$ of sodium nitrite and $10 \mathrm{~g}$ of sodium molybdate in $100 \mathrm{~mL}$ of deionized water. If catecholate-type siderophore is present, the solution presents an orange-red colour. The colour intensity is dependent of the amount of catechol present (Arnow 1937).

The Csaky's test detects hydroxamate-type siderophores and depends on oxidation to nitrite and formation of a coloured complex via diazonium coupling (Csáky 1948). Firstly, $1.0 \mathrm{~mL}$ of culture filtrate was hydrolysed with $1.0 \mathrm{~mL}$ of $6 \mathrm{~N} \mathrm{H}_{2} \mathrm{SO}_{4}$, at $130{ }^{\circ} \mathrm{C}$, for $30 \mathrm{~min}$. The solution was then buffered with the aid of $3.0 \mathrm{~mL}$ of sodium acetate $\left(350 \mathrm{~g} \mathrm{~L}^{-1}\right)$ and $1.0 \mathrm{~mL}$ of sulfanilic acid [10 $\mathrm{g} \mathrm{L}^{-1}, 30 \%$ acetic acid (v/v)] was added, followed by $0.5 \mathrm{~mL}$ of iodine solution (13 $\mathrm{g} \mathrm{L}^{-1}$, in glacial acetic acid). The solution was allowed to settle for $3-5 \mathrm{~min}$, after which the excess of iodine was neutralized by the addition of $1.0 \mathrm{~mL}$ of $20 \mathrm{~g} \mathrm{~L}^{-1}$ sodium arsenite. Finally, $1.0 \mathrm{~mL}$ of $\alpha$-naphthylamine solution [3 $\mathrm{g} \mathrm{L}^{-1}$, in $30 \%(\mathrm{v} / \mathrm{v})$ acetic acid] was added and the colour was allowed to develop for 20-30 min. The presence of hydroxamates in solution was confirmed by the presence of a deep pink colour.

Synthetic $N, N$-dihydroxy- $N, N^{\prime}$-diisopropylhexanediamide (DPH), a hydroxamate, and Azotochelin, a catecholate, were used as controls (Martins et al. 2018). As blank, $1.0 \mathrm{~mL}$ of deionised water was used in both assays.

\section{Complexation capacity assays}

The complex capability of each culture medium containing siderophore was tested using a procedure adapted from Villen et al. (2007). Briefly, to a fixed volume of 
culture filtrate, $\mathrm{FeCl}_{3}$ was added, the solution $\mathrm{pH}$ was set to $9.0 \pm 0.1$ and let to rest for $30 \mathrm{~min}$. Then, $\mathrm{pH}$ was corrected again and let to settle for $3 \mathrm{~h}$. The solution was subsequently centrifuged $(3000 \times g, 10 \mathrm{~min})$ and filtered by a $0.45 \mu \mathrm{m}$ pore size membrane. The amount of Fe in solution was then determined (see "Iron determination" bellow). A graphical representation of the ratio $[\mathrm{Fe}]_{\text {complex }} /[\mathrm{L}]$ versus $[\mathrm{Fe}]_{\text {added }} /[\mathrm{L}]$ was plotted in order to represent the iron complexation capability of the siderophore in solution; where $[\mathrm{Fe}]_{\text {complex }}$ is the concentration of Fe found in the filtrate, $[\mathrm{Fe}]_{\text {added }}$ is the total Fe concentration added and $[\mathrm{L}]$ is the concentration of siderophore determined by CAS method.

\section{Bacteria staining}

Bacterial cultures were collected and cells were fixed with $3.5 \%(\mathrm{w} / \mathrm{v})$ formaldehyde for $2 \mathrm{~h}$. Cells were then harvested by centrifugation and re-suspended in $10 \mathrm{mmol} \mathrm{L}^{-1}$ phosphate-buffered saline (PBS) solution $(\mathrm{pH} 7.0)$ with $3.5 \%(\mathrm{w} / \mathrm{v})$ formaldehyde and stored at $4{ }^{\circ} \mathrm{C}$, until to be observed.

Previously stored cells were pelleted by centrifugation and washed twice with PBS buffer (pH 7.0). Cells were resuspended in PBS buffer with $3 \mu \mathrm{mol} \mathrm{L}^{-1} 4,6$-diamidino2-phenylindole (DAPI) and incubated for $15 \mathrm{~min}$ in the dark at room temperature. DAPI is a cell membrane permeant stain, which exhibits a strong blue fluorescence upon bonded to adenine-thymine rich regions in DNA (Haugland 2005).

\section{Microscopy}

Bacteria were observed by phase-contrast or epifluorescence using a microscope with a HBO 100 mercury lamp and the A filter (excitation filter BP 340-380, dichromatic mirror 400, and suppression filter LP 425) from Leica. The images were captured with a Leica DC 300F camera (Leica Microsystems, Heerbrugg, Switzerland) using a $100 \times$ oil immersion $\mathrm{N}$ plan objective and processed using Leica IM 50-Image manager software.

\section{Iron determination}

Iron determinations in cell cultures and in complexation capacity assays were carried out by atomic absorption spectroscopy with flame atomization (AAS-FA) using a Perkin Elmer AAnalyst 400 spectrometer (Norwalk, CT, USA).

\section{Reproducibility of the results}

All experiments were repeated, independently, at least, two times. Data is presented as mean values. Growthcurves were performed in duplicate; for each time, growth was monitored in triplicate. Data reported for siderophore concentrations and iron complexation experiments are the mean \pm standard deviations of at least six determinations.

\section{Results \\ Microbial growth and siderophore production}

In the present work, it was our objective to select promissory siderophore producing bacteria that can be used in the agriculture in the correction of chlorosis, in calcareous soils. For this purpose, five bacteria (Fig. 1) were selected to cover different genus and siderophores types.

All tested bacteria were grown at $30^{\circ} \mathrm{C}$, with agitation (150 rpm), in MM broth, except $A$. vinelandii which was grown in BM broth. The pre-cultures were prepared in iron-complete media. To limit iron carryover (from ironcomplete media), which inhibit siderophore production, cells in exponential phase of growth were washed and re-inoculated in the same media but without iron. At the end of the growth, the iron concentration in culture media was below the detection limit $\left(0.09 \mathrm{mg} \mathrm{L}^{-1}\right)$ of the method used.

With the exception of $A$. vinelandii, all bacteria grown in MM had a duplication time between 1.1 and $1.8 \mathrm{~h}$ (Additional file 1: Table S1) and were in stationary phase of growth at $24 \mathrm{~h}$ of incubation (Fig. 2). A. vinelandii, a bacterium with the ability to fix atmospheric nitrogen (Hamilton et al. 2011), grew more slowly in BM broth (a culture medium without nitrogen source). Under the cultural conditions used, $A$. vinelandii presented a duplication time of about 14.4 h (Additional file 1: Table S1) and was in stationary phase at $72 \mathrm{~h}$ (Fig. 2).

The amount of biomass reached, in stationary phase, varied widely. After $24 \mathrm{~h}$ of growth, $B$. megaterium and B. subtilis reached a biomass of 1.7 and $1.5 \mathrm{mg} \mathrm{mL}^{-1}$, respectively, while $R$. radiobacter only reached a biomass of $\sim 1 \mathrm{mg} \mathrm{mL}^{-1}$ (Fig. 2). A. vinelandii had a maximum biomass less than $1 \mathrm{mg} \mathrm{mL}^{-1}$ while $P$. allii had a maximum biomass of $1.3 \mathrm{mg} \mathrm{mL}^{-1}$ (Fig. 2). In the case of $B$. subtilis, after $30 \mathrm{~h}$ of growth, a decrease of biomass was observed (Fig. 2), probably due to the formation of spores (Additional file 1: Figure S1). A similar behaviour was reported for other Bacillus species (Bharucha et al. 2013; Ait Kaki et al. 2013; Santos et al. 2014).

Siderophore production was followed and compared, over time, using the CAS method (Alexander and Zuberer 1991). Under the cultural conditions tested (culture medium composition, temperature and agitation), the siderophore concentration found in the culture filtrates of $B$. megaterium reached the maximum level at $24 \mathrm{~h}$ (Fig. 3), when the bacterium was in stationary phase (Fig. 2). After this time, the level of siderophore remained stable (Fig. 3). Although delayed, a similar pattern of siderophore production was observed for $A$. vinelandii. Siderophore concentration 

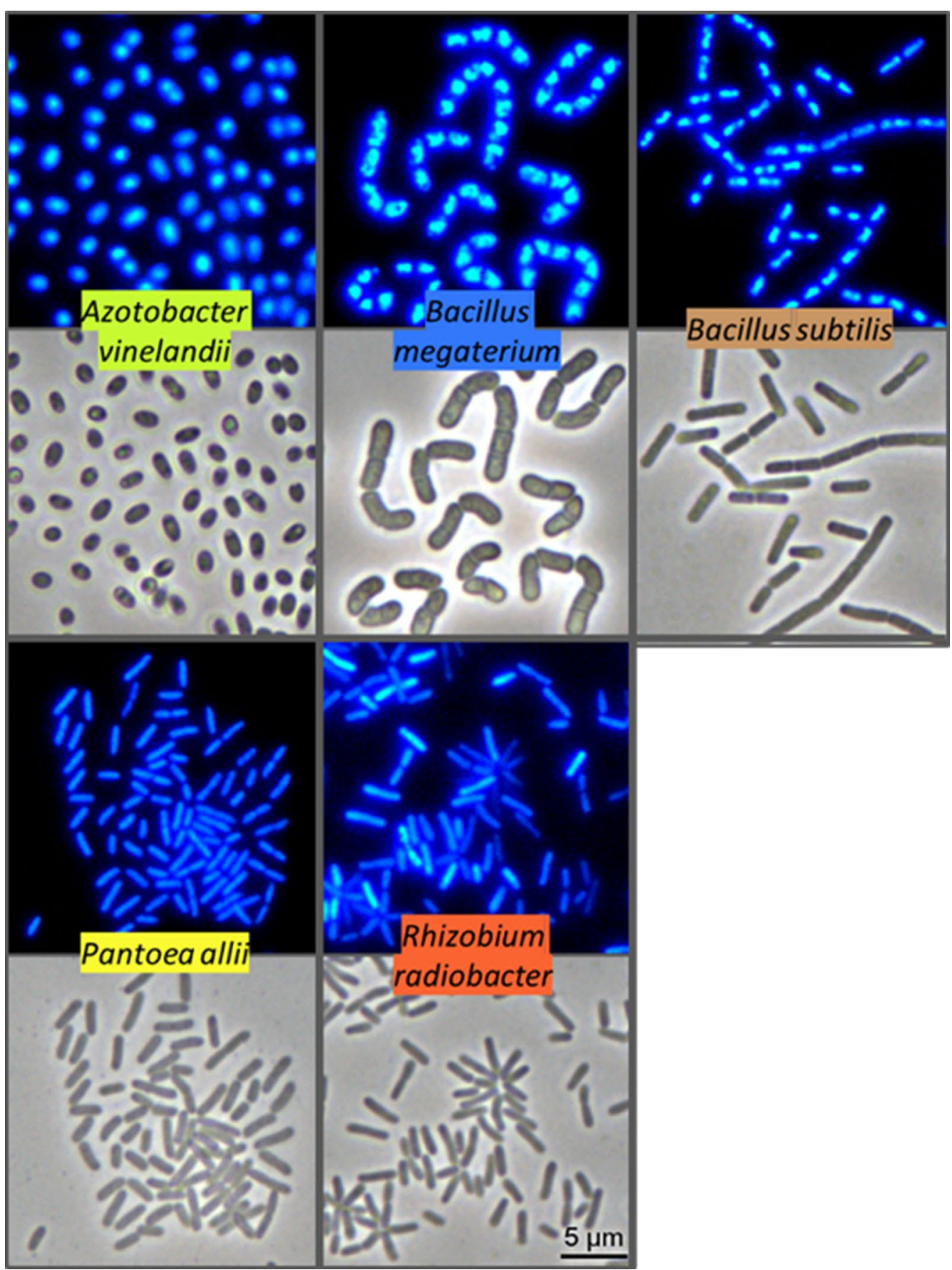

Fig. 1 Visualization of the morphology of the bacteria studied. Microphotographs illustrative of the bacteria stained with DAPI and observed by fluorescent microscopy (upper images) or by phase-contrast microscopy (lower images). All microphotographs were taken in cultures with cells in exponential phase of growth: $6 \mathrm{~h}$ for all strains, except A. vinelandii (48 h)

in $B$. subtilis and $P$. allii filtrates were also relatively stable from 24 to $48 \mathrm{~h}$ of growth; only a small increase or decrease of the mean values were observed at $48 \mathrm{~h}$, respectively (Fig. 3). In the case of $R$. radiobacter, an increase of the mean value of siderophore production was observed between 24 and 48 h (Fig. 3). 


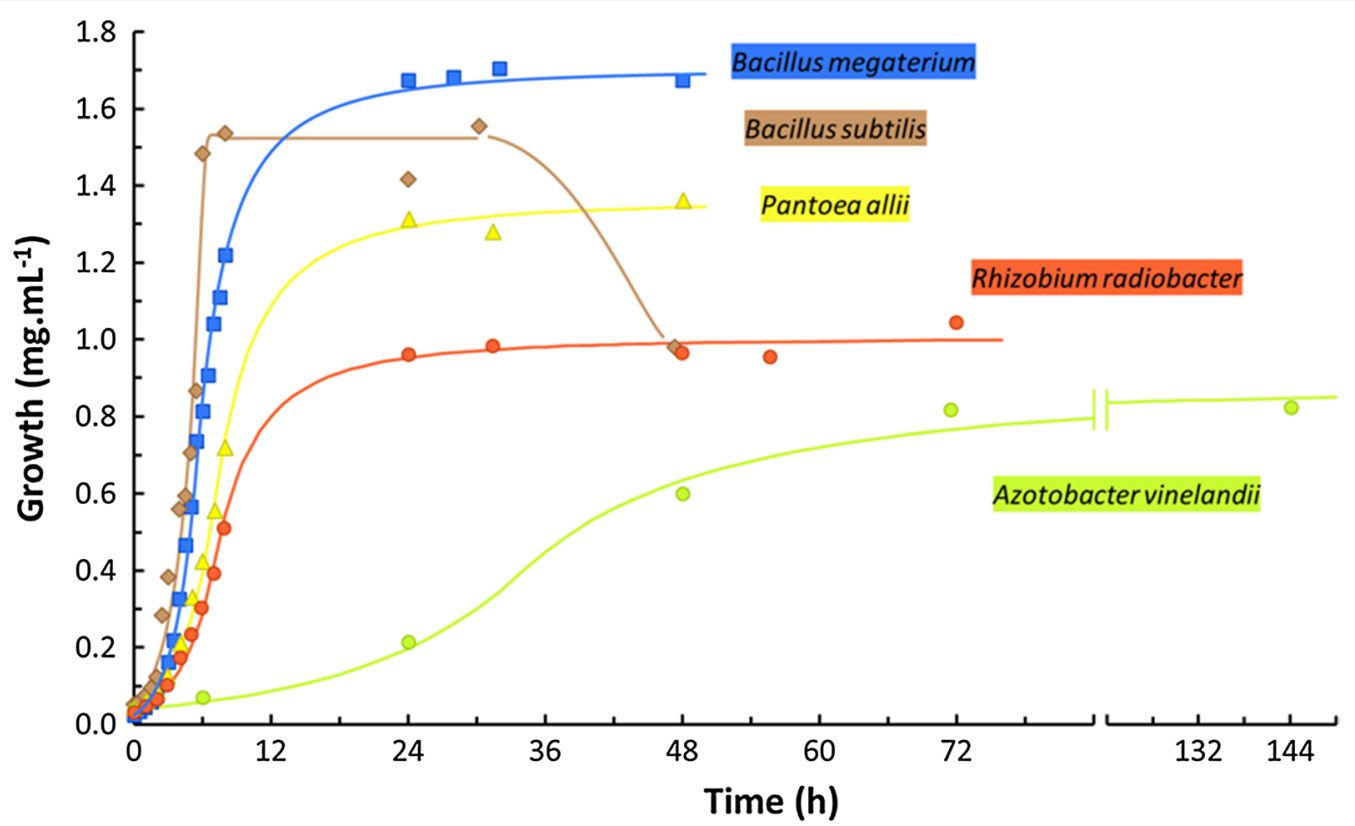

Fig. 2 Growth of the bacteria studied. The bacteria, in exponential phase of growth, were inoculated in minimal medium (MM) broth (except $A$. vinelandii, which was inoculated in Burk's medium broth), iron-deficient, and incubated at $30^{\circ} \mathrm{C}$ with agitation (150 rpm). This is a typical example of an experiment performed at least two times. Each point represents the average of three determinations

\section{Siderophore qualification}

The type of siderophore present in each medium filtrate was tested using the Arnow's and Csaky's tests. Arnow's test allows the identification of the presence of catechol groups in siderophores, while Csaky's test is used to identify the presence of hydroxamic groups (Arnow 1937; Csáky 1948).

Azotobacter vinelandii had a positive result for both Arnow's and Csaky's test, which indicates the presence of both catechol and hydroxamate siderophores in the filtrate of the culture medium (Table 1; Additional file 1: Figure S3). The two Bacillus species studied produce different siderophore types. B. megaterium had a strong reaction to Csaky's and none to Arnow's, which indicate the presence of a hydroxamate-type siderophore in the supernatant of the culture. B. subtilis had a strong positive reaction with the Arnow's test and no reaction in Csaky's, which suggest the presence of catechol-type siderophore (Table 1; Additional file 1: Figure S3). $R$. radiobacter filtrate also presented a positive result for Arnow's test, which indicates that this microorganism produces a catechol-type siderophore. P. allii had a positive result on Csaky's test, which suggests the presence of hydroxamate-type siderophores in the filtrate (Table 1; Additional file 1: Figure S3).

\section{Iron complexation capacity}

The problem of plant chlorosis is particularly critical under alkaline conditions due to the low concentration of iron bioavailable (Hansen et al. 2006; Colombo et al. 2014). Bacterial filtrates can be further used in the preparation of siderophore concentrate intended to be used in the chlorosis amendment in calcareous soils. In order to assess the iron chelating potential of the culture filtrates, for the $\mathrm{pH}$ range typical of calcareous agronomic conditions ( $\mathrm{pH} 9.0)$, the bacterial culture filtrates were subjected to the procedure described in "Materials and methods", "Complexation capacity assays".

The main results of the complexation capacity assays are shown in Fig. 4. In regard to B. megaterium and $B$. subtilis, the initial slopes of the experimental data are close to 1 (dashed line) up to a $[\mathrm{Fe}]_{\text {added }} /[$ Siderophore $]$ ratio of about 2 and 2.5 , respectively, which indicates that iron is being complexed with fairly good effectiveness up to that amount of iron added. For $A$. vinelandii, although some early deviations are seen, the only major shift from the slope $=1$ is seen at $[\mathrm{Fe}]_{\text {added }} /$ [Siderophore $]$ ratio of about 1.5. At this point, an efficiency of about $75 \%$ is observed with $[\mathrm{Fe}]_{\text {added }} /[$ Siderophore $]$ of 1.5 corresponding to a $[\mathrm{Fe}]_{\text {soluble }} /[$ Siderophore $]$ of 1 . In both cases, early deviations may be related to inefficient complexation in the $\mathrm{pH}$ range used $(\mathrm{pH} 9.0 \pm 0.1)$; on the other hand, more severe deviations observed for higher $[\mathrm{Fe}]_{\text {added }} /[$ Siderophore $]$ ratios are more likely due to the complexation of weaker siderophores/chelating agents, where the added iron is not effectively complexed and promptly precipitates. 

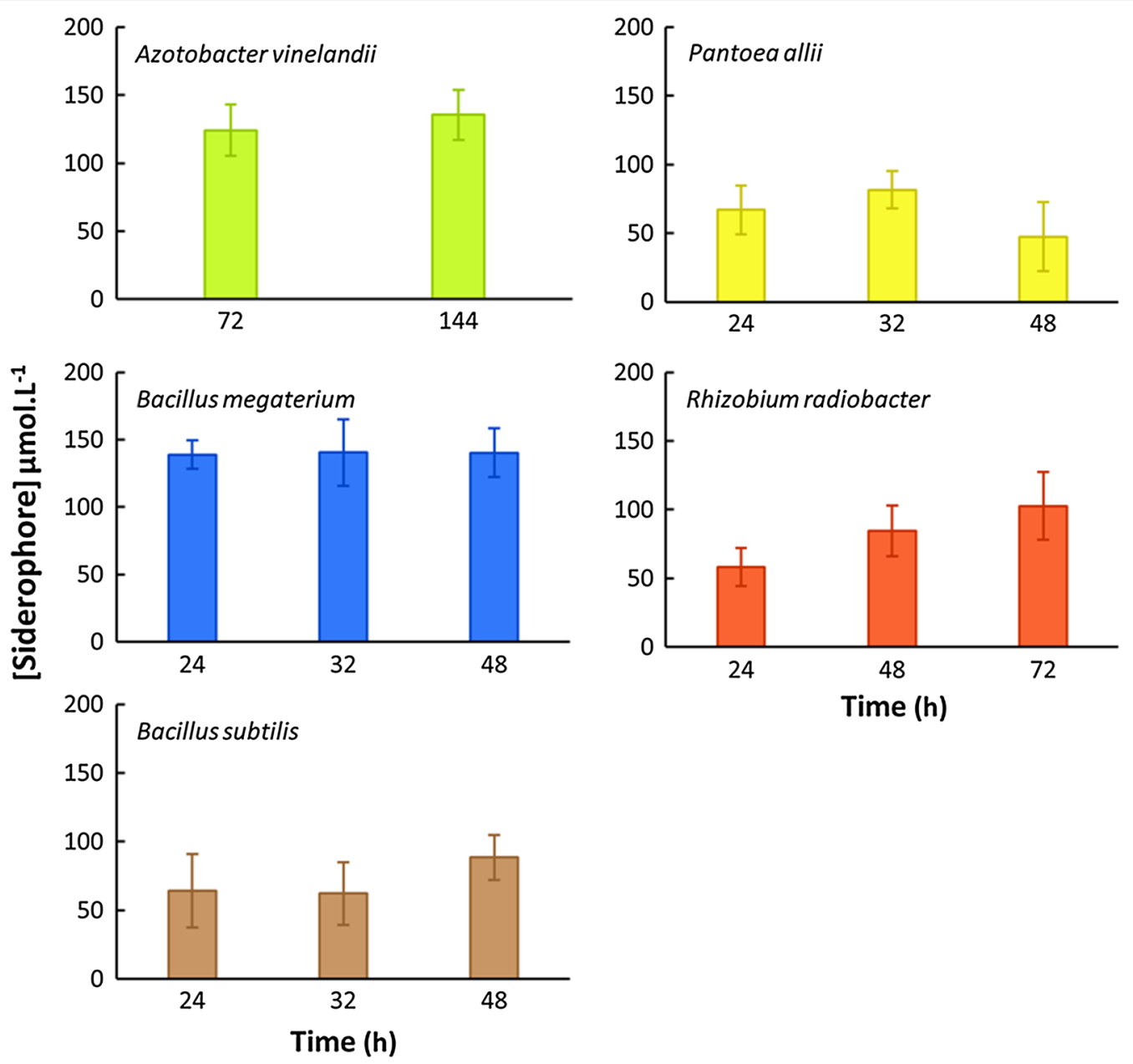

Fig. 3 Siderophore production by the different bacteria tested. Siderophore was quantified by CAS assay on culture filtrates and expressed as

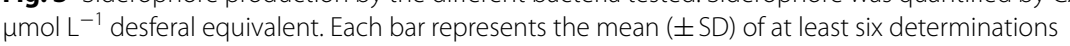

Table 1 Characterization produced by the bacteria

\begin{tabular}{lll}
\hline Bacteria & Arnow $^{\mathbf{a}}$ & Csaky $^{\mathbf{a}}$ \\
\hline Azotobacter vinelandii & + & + \\
Bacillus megaterium & - & ++ \\
Bacillus subtilis & ++ & - \\
Pantoea allii & - & + \\
Rhizobium radiobacter & + & - \\
\hline
\end{tabular}

a Catechol- and hydroxamate-type siderophores were identified using Arnow' and Csaky's tests, respectively. ++ strong positive result; + positive result; negative result

For each culture filtrate, based on the values of highest $[\mathrm{Fe}]_{\text {added }} /[$ Siderophore $]$, one can, based upon CAS values, estimate the amount of Fe efficiently complexed. For example, in the case of $A$. vinelandii filtrate, considering a CAS reading of $140 \mu \mathrm{mol} \mathrm{L} \mathrm{L}^{-1}$, one can expect to have $140 \mu \mathrm{mol} \mathrm{L} \mathrm{L}^{-1}$ of dissolved iron upon addition of about $210 \mu \mathrm{mol} \mathrm{L}^{-1}$ of Fe $\left(1.5 \times 140 \mu \mathrm{mol} \mathrm{L}^{-1}\right)$. Likewise, a B. subtilis filtrate, with a CAS reading of $100 \mu \mathrm{mol} \mathrm{L}^{-1}$, is expected to be able to dissolve the entirety of $250 \mu \mathrm{mol} \mathrm{L}-1$ of added Fe $\left(2.5 \times 100 \mu \mathrm{mol} \mathrm{L}^{-1}\right)$.

On the other hand, $P$. allii and $R$. radiobacter evidenced lower slopes from early on, which is somehow contradictory to what would be expected. For example, literature describes that $R$. radiobacter produces agrobactin, which complex iron in a 1:1 ratio, in an hexadentate conformation; thus, a slope close to 1 would be expected (Fig. 4) as a result of the high complex stability and consequent effectiveness of complexation. The observed results may be due to the lower efficiency for chelating iron at this $\mathrm{pH}$ and/or due to the presence of other(s) siderophore(s) with a different stoichiometry (and stability). Due to the lack of information of the siderophores produced by $P$. allii and the results shown in Fig. 4, it is possible that 

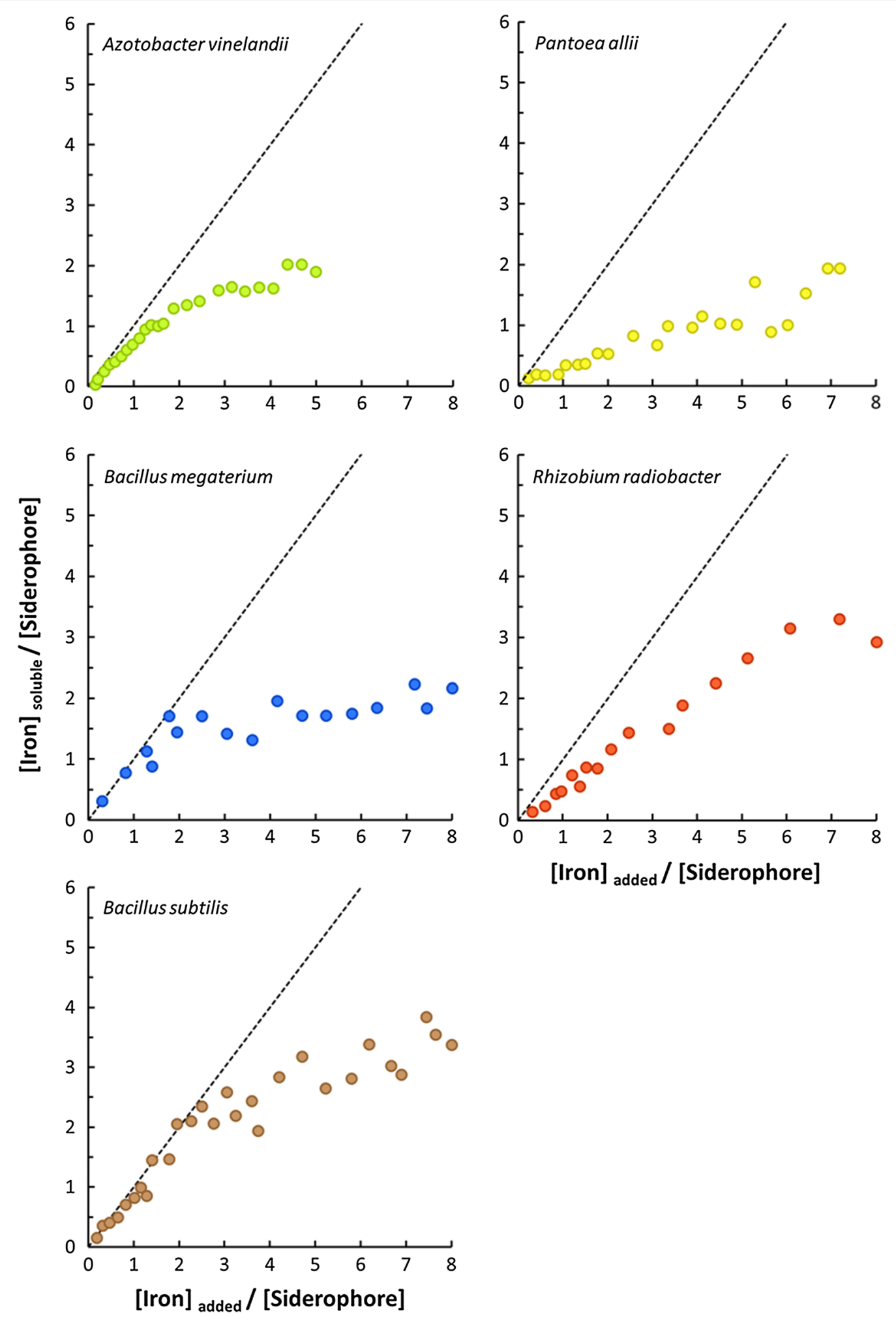

Fig. 4 Average of complexed iron versus added iron as function of total siderophore concentration as determined by CAS method. Dashed grey line represents a line with slope $=1$ 
the siderophores produced are not of the 1:1 type, as it is the case of enterobactin, desferrioxamine, and aerobactin, which were described for others species of Pantoea (Soutar and Stavrinides 2018). Nonetheless, in case of a 1:1 complexation, the complexed formed may not be very strong and, thus, not capable of complexing most iron added at $\mathrm{pH}$ 9.0.

\section{Discussion}

\section{Definition of the culture time for siderophore production}

It was our aim to select microorganisms producers of efficient siderophores, such as catecholates and hydroxamates, since these compounds display the highest affinity to iron (Hider and Kong 2010). A search in the literature revealed the presence of more than 20 bacteria genera that produces these siderophore-types (Bhattacharyya and Jha 2012; Ferreira et al. 2019b; Hider and Kong 2010). From these, only bacterial strains non-pathogenic to humans (risk 1 group) (U.S. Department of Health and Human Sevices et al. 2009) were considered as adequate for this work.

In a general way, the maximum level of siderophore in cultures filtrates was attained when the bacteria entered the stationary phase (Figs. 2 and 3). The amount of siderophore produced remained approximately constant after $24 \mathrm{~h}$ for B. megaterium, B. subtilis and P. allii or after $72 \mathrm{~h}$ for $A$. vinelandii. Only for $R$. radiobacter, a small increase of siderophore production was observed in the beginning of the stationary phase (24-48 h) (Figs. 2 and 3). Unless for $A$. vinelandii, these results indicate that, for future siderophore production using these bacteria, it is not necessary to prolong the culture more than $48 \mathrm{~h}$; for $A$. vinelandii, it is necessary to prepare a culture with $72 \mathrm{~h}$.

The pattern of growth and the siderophore production of $B$. subtilis strain studied are in agreement with those described in the literature (Patel et al. 2009). However, under the cultural conditions used in the present work, the strain presented a higher level of siderophore compared to that described by Miethke et al. (2006) using a minimal culture medium. Also, a faster maximum concentration of siderophore production was achieved with our conditions than those used by Fazary et al. (2016a) to grow Bacillus spp. ST13. In the present work, for the bacterium $B$. megaterium, the maximum concentration of siderophore was found when the cultured reached the stationary phase (Figs. 2 and 3). Using a different culture medium and different cultural conditions, it was described that $B$. megaterium continued to produce siderophore during the stationary phase (Santos et al. 2014). A similar pattern was here observed, between 24 and $48 \mathrm{~h}$, with $R$. radiobacter. Using a different
Rhizobium species (R. militoli and a Rhizobium strain, isolated from cowpea), a maximum siderophore production was described after $24 \mathrm{~h}$ of growth (Jadhav and Desai 1992; Reigh 1991).

\section{Selection of the best iron complexation performance under alkaline conditions}

As reported above, strains producers of catecholate and/ or hydroxamate-type siderophores are desirable due to the high iron binding capacity of these compounds. Therefore, to confirm the presence of such compounds in the bacterial filtrates, the respective siderophore qualification was carried out.

Several siderophores have been described for A. vinelandii, namely azotobactin, previously known as yellowgreen fluorescent peptide (Bulen and LeComte 1962), 2,3-dihydroxybenzoic acid, azotochelin (Corbin and Bulen 1969), aminochelin (Page and Tigerstrom 1988) and protochelin (Cornish and Page 1995), which are, respectively, mono-, mono-, di-, mono- and tri-catecholates. Vibrioferrin, another siderophore described (McRose et al. 2017), has two hydroxy-carboxylate moieties which should not react in Csaky and Arnow tests. Finally, azotobactin has a complex structure in which a catechol and a hydroxamate moieties can be found (Duhme et al. 1998). The positive result obtained in both tests (Table 1), can be attributed to the possible presence of azotobactin, aminochelin, azotochelin or/and protochelin. Given the less intense colour developed in the case of Azotobacter culture compared to the one observed in the case of B. subtilis (Additional file 1: Figure S3), a lower quantity of catecholate may be expected. Considering the similar average molar quantities of siderophores on $B$. subtilis and $A$. vinelandii filtrates evaluated by CAS $\left(\sim 100 \mu \mathrm{mol} \mathrm{L}^{-1}\right.$ vs $\left.\sim 120 \mu \mathrm{mol} \mathrm{L}^{-1}\right)$ and the more intense colour developed by $B$. subtilis compared to $A$. vinelandii, these facts suggest that the number of catechol sites per molecule may be lower in the case of $A$. vinelandii filtrates. Therefore, the presence of mono and di catecholates, such as azotobactin, aminochelin and/or azotochelin is very likely. Given the positive result for Csaky's test and the fluorescent hue of the filtrate (Additional file 1: Figure S2), the presence of azotobactin is very plausible. The positive result in Csaky's test for B. megaterium is in agreement with the literature, which describes the production of schizokinen and its derivatives by this bacterium, under ironlimited conditions (Mullis et al. 1971). Schizokinen is a di-hydroxamate siderophore with a citrate backbone (Goldman et al. 1983; Hu and Boyer 1995). On the other hand, the positive result in Arnow's test for B. subtilis is compatible with the literature, which describes the 
ability of this bacterium to produces bacillibactin (a tricatecholate siderophore, which has a 1:1 coordination with iron) and, to a less extent, the more simple itoic acid, with a coordination of 3:1 (Dertz et al. 2006). $R$. radiobacter also presented a positive result in Arnow's test; this result is in agreement with the literature, which describes the ability of $R$. radiobacter to produce agrobactin, a tri-catecholate with a structure simpler than the one produced by B. subtilis (Ong et al. 1979). For $P$. allii, little information regarding siderophore production and/or structure has been published. Although it was described that a strain similar to $P$. allii had great siderophore production capacity, no information regarding the type of siderophore was provided (Pereira and Castro 2014). For other Pantoea species, a recent genomewide survey has found three gene clusters homologous to those of enterobactin (catecholate-type siderophore), desferrioxamine (hydroxamate-type siderophore), and aerobactin (hydroxamate-type siderophore) (Soutar and Stavrinides 2018). These findings are in agreement with the results found for $P$. allii as a hydroxamate-type siderophore producer (Csaky positive test).

Even though all bacteria tested in this work evidenced siderophore production of similar order of magnitude (Fig. 3) (when evaluated by the CAS assay and expressed as $\mu \mathrm{mol} \mathrm{L} \mathrm{L}^{-1}$ desferal equivalent), these results do not mean that these culture filtrates have ability to complex Fe at high $\mathrm{pH}$ conditions, which represent the real situation that the complexes have to endure when they are applied in alkaline soils.

The siderophores present in the culture filtrates of $A$. vinelandii, B. megaterium and B. subtilis evidenced high stability to complex $\mathrm{Fe}$ at $\mathrm{pH} 9.0$ in a wide range of $[\mathrm{Fe}]_{\text {added }} /[$ Siderophore $]$ (up to 1.5, 2.0 and 2.5, respectively) whereas the other two cultures ( $P$. allii and $R$. radiobacter) revealed weaker ability (Fig. 4). $R$. radiobacter produces agrobactin, which complex iron in a 1:1 ratio, in a hexadentate conformation; thus, a slope close to 1 would be expected (Fig. 4) as a result of the high complex stability and consequent effectiveness of complexation. In this work, the weaker complexation capacity may be due to the lower efficiency for chelating iron at this $\mathrm{pH}$ and/or due to the presence of other(s) siderophore(s) with a different stoichiometry (and stability). Due to the lack of information of the siderophores produced by $P$. allii and the results shown in Fig. 4, it is possible that the siderophores produced are not of the 1:1 type, as it is the case of enterobactin, desferrioxamine, and aerobactin, which were described for others species of Pantoea (Soutar and Stavrinides 2018). Nonetheless, in case of a 1:1 complexation, the complexed formed may not be very strong and, thus, not capable of complexing most iron added at $\mathrm{pH} 9.0$.

\section{Overall comparison of bacteria performance}

In order to select the strain(s) producer(s) of siderophores with potential ability to be subsequently tested for correcting iron chlorosis in plants, the performance of the bacteria was compared regarding the following characteristics: iron complexation capacity at $\mathrm{pH} 9.0$; siderophore type; growth and handling of the strain: growth rate, nutritional requirements (culture media composition) and easiness of biomass separation from the culture medium (Table 2).

Azotobacter vinelandii, B. megaterium and B. subtilis revealed to be the bacteria with the best performance since the respective medium filtrate had the ability to complex iron efficiently at $\mathrm{pH} 9.0$ with the highest iron complexation capacity (Table 2). This is an indispensable condition for the culture filtrates to be used in the preparation of a siderophore concentrate intended for chlorosis amendment in calcareous soils. Also, the culture media used for bacterial growth are cheap since they are only composed by mineral salts and glucose. In the case of BM broth (used for $A$. vinelandii), the medium is selective due to the lack of nitrogen source, which reduces the risk of culture contamination during the biotechnological production of the siderophore. The low growth rate of $A$. vinelandii (Additional file 1: Table S1) is not a hindrance to the industrial use of this bacterium since the maximum concentration is achieved within $72 \mathrm{~h}$, which is a culture time in the same order of magnitude of the other bacteria studied. Probably, due to its size (Fig. 1) and clump formation, biomass separation of $A$. vinelandii and $B$. megaterium by centrifugation/filtration is easy to perform. However, in the case of B. megaterium, sporulation should be avoided as spores will make filtration more difficult. To avoid this problem, the bacteria should not be left to grow more than $48 \mathrm{~h}$ (Fig. 2). Biomass separation

Table 2 Summary of the main properties of the bacteria studied

\begin{tabular}{llll}
\hline Bacteria & $\begin{array}{l}\text { Average } \\
\text { complexation } \\
\text { capacity at } \mathbf{p H ~ 9 . 0} \\
\left(\mu \mathrm{mol} \mathrm{L} \mathbf{- 1}^{-1}\right.\end{array}$ & $\begin{array}{l}\text { Siderophore } \\
\text { type }^{\mathbf{a}}\end{array}$ & $\begin{array}{l}\text { Growth } \\
\text { and handling }\end{array}$ \\
\hline $\begin{array}{l}\text { Azotobacter } \\
\text { vinelandii }\end{array}$ & 188 & $\mathrm{C}+\mathrm{H}$ & +++ \\
$\begin{array}{l}\text { Bacillus megate- } \\
\text { rium }\end{array}$ & 280 & $\mathrm{H}$ & +++ \\
$\begin{array}{l}\text { Bacillus subtilis } \\
\text { Pantoea allii }\end{array}$ & 225 & $\mathrm{C}$ & + \\
$\begin{array}{l}\text { Rhizobium radio- } \\
\text { bacter }\end{array}$ & Weak & $\mathrm{H}$ & + \\
\end{tabular}

\footnotetext{
a Siderophore type: $\mathrm{C}=$ catecholate; $\mathrm{H}=$ hydroxamate

b Growth and handling: it was considered the growth rate of the bacteria, culture media composition and easiness of the bacterial removal by centrifugation/filtration 
of B. subtilis, by centrifugation/filtration, presented some difficulties, which can be attributed to the relatively small size of the bacterium (Fig. 1). It also suffers from sporulation issues as $B$. megaterium.

The siderophores produced by $P$. allii and $R$. radiobacter, presented inefficient iron-complexation capacity at pH 9.0 (Table 2), which prevent their use for agricultural purposes. P. allii suffers from the same handling issues reported for B. subtilis. Probably, due to their small size (Fig. 1), these bacteria easily clog the pores, being hard to filter.

In conclusion, in the present study, the performance of five bacteria was studied in view of their potential use for iron-induced chlorosis amendment in calcareous soils. $A$. vinelandii, $B$. megaterium and $B$. subtilis were the most promising, taking into account their strong iron complexation capacity at $\mathrm{pH} 9.0$ (this is an important parameter if correction of iron-induced chlorosis in plants grown in calcareous soils is the aim) and the type of siderophore produced (catechol and hydroxamate). The three bacteria also presented the maximum siderophore production, evaluated by CAS assay, between 24 and $72 \mathrm{~h}$, did not require expensive ingredients in culture media formulation and are easily removed (except $B$. subtilis) from the culture medium by centrifugation/filtration.

\section{Additional file}

Additional file 1: Figure S1. Microphotographs illustrative of the morphology of $B$. subtilis in stationary phase of growth (culture at $48 \mathrm{~h}$ ). Figure S2. Representative photographs of microbial filtrate at different times of growth. Figure S3. Qualification of the siderophores produced by the bacteria. Table S1. Duplication time and growth media for the bacteria studied.

\section{Acknowledgements}

C.M.H. Ferreira would like to thank the support from his grant with reference SFRH/BD/95490/2013 from FCT.

\section{Authors' contributions}

HMVMS and EVS designed research; CMHF, AV-B and CAS, performed experimental research under the supervision of EVS and HMVMS; EVS, HMVMS and $\mathrm{CMHF}$, analysed data; EVS, HMVMS and CMHF, wrote the paper. All authors read and approved the final manuscript.

\section{Funding}

This work is financed by the FEDER funds through the Operational Competitiveness Factors Program - COMPETE and by national funds through FCT-Foundation for Science and Technology within the scope of the project PTDC-AGR-TEC/0458/2014_POCI-01-0145-FEDER-016681.

\section{Availability of data and materials}

All data analysed throughout this study are shown in this article. All strains and reagents were purchased in microbial collections or in companies, respectively, specified in the text.

\section{Consent for publication}

Not applicable.

\section{Ethics approval and consent to participate}

Not applicable. This article does not contain any studies with human participants or animals performed by any of the authors.

\section{Competing interests}

The authors declare that they have no competing interests.

\section{Author details}

${ }^{1}$ REQUIMTE/LAQV, Departamento de Engenharia Química, Faculdade de Engenharia, Universidade do Porto, rua Dr. Roberto Frias, 4200-465 Porto, Portugal. ${ }^{2}$ Bioengineering Laboratory-CIETI, Chemical Engineering Department, ISEP-School of Engineering of Polytechnic Institute of Porto, rua Dr António Bernardino de Almeida, 431, 4249-015 Porto, Portugal. ${ }^{3}$ CEB-Centre of Biological Engineering, University of Minho, 4710-057 Braga, Portugal.

Received: 28 April 2019 Accepted: 13 May 2019

Published online: 28 May 2019

\section{References}

Ait Kaki A, Kacem Chaouche N, Dehimat L, Milet A, Youcef-Ali M, Ongena M, Thonart P (2013) Biocontrol and plant growth promotion characterization of Bacillus species isolated from Calendula officinalis rhizosphere. Indian J Microbiol 53:447-452. https://doi.org/10.1007/s12088-013-0395-y

Alexander DB, Zuberer DA (1991) Use of chrome azurol S reagents to evaluate siderophore production by rhizosphere bacteria. Biol Fertil Soils 12:39-45. https://doi.org/10.1007/BF00369386

Arnow LE (1937) Colorimetric determination of the components of 3,4-dihydroxyphenylalanine-tyrosine mixtures. J Biol Chem 118:531-537. https:// doi.org/10.1126/science.86.2225.176

Barker AV, Stratton ML (2015) Iron. In: Barker AV, Pilbeam DJ (eds) Handbook of plant nutrition, 2nd edn. CRC Press, Boca Raton, pp 399-426

Bharucha UD, Patel KC, Trivedi UB (2013) Antifungal activity of catecholate type siderophore produced by Bacillus sp. Int J Res Pharm Sci 4:528-531

Bhattacharyya PN, Jha DK (2012) Plant growth-promoting rhizobacteria (PGPR): emergence in agriculture. World J Microbiol Biotechnol 28:13271350. https://doi.org/10.1007/s11274-011-0979-9

Broadley M, Brown P, Cakmak I, Rengel Z, Zhao F (2012) Function of nutrients. In: Marschner P (ed) Marschner's mineral nutrition of higher plants, 3rd edn. Elsevier, Hoboken, pp 191-248

Bucheli-Witschel M, Egli T (2001) Environmental fate and microbial degradation of aminopolycarboxylic acids. FEMS Microbiol Rev 25:69-106. https ://doi.org/10.1016/S0168-6445(00)00055-3

Bulen WA, LeComte JR (1962) Isolation and properties of a yellow-green fluorescent peptide from Azotobacter medium. Biochem Biophys Res Commun 9:523-528. https://doi.org/10.1016/0006-291X(62)90119-5

Chaney RL, Chen Y, Green CE, Holden MJ, Bell PF, Luster DG, Angle JS (2008) Root hairs on chlorotic tomatoes are an effect of chlorosis rather than part of the adaptive Fe-stress-response. J Plant Nutr 15:1857-1875. https ://doi.org/10.1080/01904169209364444

Cianzio SR, Shoemaker RC, Charlson DV (2006) Genomic resources of agronomic crops. In: Barton LL (ed) Iron nutrition in plants and rhizospheric microorganisms. Springer, Netherlands, pp 449-466

Colombo C, Palumbo G, He J-Z, Pinton R, Cesco S (2014) Review on iron availability in soil: interaction of Fe minerals, plants, and microbes. J Soils Sediments 14:538-548. https://doi.org/10.1007/s11368-013-0814-z

Corbin JL, Bulen WA (1969) Isolation and identification of 2,3-dihydroxybenzoic acid and.N2, N6-di(2,3-dihydroxybenzoyl)-L-lysine formed by iron-deficient Azotobacter vinelandii. Biochemistry 8:757-762. https:// doi.org/10.1021/bi00831a002

Cornish AS, Page WJ (1995) Production of the triacetecholate siderophore protochelin by Azotobacter vinelandii. Biometals 8:332-338. https://doi. org/10.1007/BF00141607

Csáky TZ (1948) On the estimation of bound hydroxylamine in biological materials. Acta Chem Scand 2:450-454. https://doi.org/10.3891/acta. chem.scand.02-0450

Dertz EA, Xu J, Stintzi A, Raymond KN (2006) Bacillibactin-mediated iron transport in Bacillus subtilis. J Am Chem Soc 128:22-23. https://doi. org/10.1021/ja055898c 
Duhme AK, Hider RC, Naldrett MJ, Pau RN (1998) The stability of the molybdenum-azotochelin complex and its effect on siderophore production in Azotobacter vinelandii. J Biol Inorg Chem 3:520-526. https://doi. org/10.1007/s007750050263

Fazary AE, Al-Shihri AS, Alfaifi MY, Saleh KA, Alshehri MA, Elbehairi SEl, Ju Y-H (2016a) Microbial production of four biodegradable siderophores under submerged fermentation. Int J Biol Macromol 88:527-541. https://doi. org/10.1016/j.ijbiomac.2016.03.011

Fazary AE, Ju YH, Al-Shihri AS, Alfaifi MY, Alshehri MA (2016b) Biodegradable siderophores: survey on their production, chelating and complexing properties. Rev Inorg Chem 36:153-181. https://doi.org/10.1515/revic -2016-0002

Ferreira CMH, Sousa CA, Sanchis-Pérez I, López-Rayo S, Barros MT, Soares HMVM, Lucena JJ (2019a) Calcareous soil interactions of the iron(III) chelates of DPH and Azotochelin and its application on amending iron chlorosis in soybean (Glycine max). Sci Total Environ 647:1586-1593. https ://doi.org/10.1016/j.scitotenv.2018.08.069

Ferreira CMH, Soares HMVM, Soares EV (2019b) Promising bacterial genera for agricultural practices: an insight on plant growth-promoting properties and microbial safety aspects. Sci Total Environ. https://doi.org/10.1016/j. scitotenv.2019.04.225

Froechlich DM, Fehr WR (1981) Agronomic performance of soybeans with differing levels of iron deficiency chlorosis on calcareous Soil. Crop Sc 21:438-441. https://doi.org/10.2135/cropsci1981.0011183X0021000 $30021 x$

Goldman SJ, Lammers PJ, Berman MS, Sanders-Loehr J (1983) Siderophoremediated iron uptake in different strains of Anabaena sp. J Bacteriol 156:1144-1150

Grobelak A, Hiller J (2017) Bacterial siderophores promote plant growth: screening of catechol and hydroxamate siderophores. Int J Phytoremediat 19:825-833. https://doi.org/10.1080/15226514.2017.1290581

Guerinot ML, Yi Y (1994) Iron: nutritious, noxious, and not readily available. Plant Physiol 104:815-820. https://doi.org/10.1104/pp.104.3.815

Hamilton TL, Ludwig M, Dixon R, Boyd ES, Dos Santos PC, Setubal JC, Bryant DA, Dean DR, Peters JW (2011) Transcriptional profiling of nitrogen fixation in Azotobacter vinelandii. J Bacteriol 193:4477-4486. https://doi. org/10.1128/JB.05099-11

Hansen NC, Hopkins BG, Ellsworth JW, Jolley VD (2006) Iron nutrition in field crops. In: Barton LL, Abadia J (eds) Iron nutrition in plants and rhizospheric microorganisms, First. Springer, Netherlands, pp 23-59

Haugland RP (2005) The handbook: a guide to fluorescent probes and labeling technologies, 10th edn. Invitrogen Corp, Carlsbad

Hider RC, Kong X (2010) Chemistry and biology of siderophores. Nat Prod Rep 27:637-657. https://doi.org/10.1039/b906679a

HiMedia Laboratories (2015) Burks Medium—M707. Mumbai, India. http:// himedialabs.com/TD/M707.pdf. Accessed 15 May 2015

Hu X, Boyer GL (1995) Isolation and characterization of the siderophore $\mathrm{N}$-deoxyschizokinen from Bacillus megaterium ATCC 19213. Biometals 8:357-364

Jadhav RS, Desai AJ (1992) Isolation and characterization of siderophore from cowpea Rhizobium (peanut isolate). Curr Microbiol 24:137-141. https:// doi.org/10.1007/BF01568978

Kabir AH, Paltridge N, Stangoulis J (2016) Chlorosis correction and agronomic biofortification in field peas through foliar application of iron fertilizers under Fe deficiency. J Plant Interact 11:1-4. https://doi. org/10.1080/17429145.2015.1125534

Leydier A, Lecerclé D, Pellet-Rostaing S, Favre-Reguillon A, Taran F, Lemaire M (2008) Sequestering agent for uranyl chelation: a new family of CAMS ligands. Tetrahedron 64:6662-6669. https://doi.org/10.1016/j. tet.2008.05.021

Liu D, Yang Q, Ge K, Hu X, Qi G, Du B, Liu K, Ding Y (2017) Promotion of iron nutrition and growth on peanut by Paenibacillus illinoisensis and Bacillus sp. strains in calcareous soil. Brazilian J Microbiol 48:656-670. https ://doi.org/10.1016/j.bjm.2017.02.006

Lucena JJ (2000) Effects of bicarbonate, nitrate and other environmental factors on iron deficiency chlorosis. A review. J Plant Nutr 23:15911606. https://doi.org/10.1080/01904160009382126

Lucena JJ (2003) Fe chelates for remediation of Fe chlorosis in strategy I plants. J Plant Nutr 26:1969-1984. https://doi.org/10.1081/PLN-12002 4257
Martins JG, Martin C, Hernández-Apaolaza L, Barros MT, Soares HMVM, Lucena JJ (2018) Azotochelin and N-dihydroxy-N, N'-diisopropylhexanediamide as Fe sources to cucumber plants in hydroponic cultures. Emirates J Food Agric 30:65-76. https://doi.org/10.9755/ejfa.2018.v30. i1.1586

McRose DL, Baars O, Morel FMM, Kraepiel AML (2017) Siderophore production in Azotobacter vinelandii in response to Fe-, Mo- and V-limitation. Environ Microbiol 19:3595-3605. https://doi.org/10.1111/1462-2920.13857

Miethke M, Klotz O, Linne U, May JJ, Beckering CL, Marahiel MA (2006) Ferribacillibactin uptake and hydrolysis in Bacillus subtilis. Mol Microbiol 61:1413-1427. https://doi.org/10.1111/j.1365-2958.2006.05321.x

Mullis KB, Pollack JR, Neilands JB (1971) Structure of schizokinen, an iron-transport compound from Bacillus megaterium. Biochemistry 10:4894-4898. https://doi.org/10.1021/bi00802a010

Ong SA, Peterson T, Neilands JB (1979) Agrobactin, a siderophore from Agrobacterium tumefaciens. J Biol Chem 254:1860-1865

Page WJ, Tigerstrom MV (1988) Aminochelin, a catecholamine siderophore produced by Azotobacter vinelandii. Microbiology 134:453-460. https:// doi.org/10.1099/00221287-134-2-453

Patel AK, Deshattiwar MK, Chaudhari BL, Chincholkar SB (2009) Production, purification and chemical characterization of the catecholate siderophore from potent probiotic strains of Bacillus spp. Bioresour Technol 100:368-373. https://doi.org/10.1016/j.biortech.2008.05.008

Payne SM (1994) Detection, isolation, and characterization of siderophores. Methods Enzymol 235:329-344. https://doi.org/10.1016/00766879(94)35151-1

Pereira SIA, Castro PML (2014) Diversity and characterization of culturable bacterial endophytes from Zea mays and their potential as plant growth-promoting agents in metal-degraded soils. Environ Sci Pollut Res 21:14110-14123. https://doi.org/10.1007/s11356-014-3309-6

Reigh G (1991) Analysis of siderophore production by Rhizobium meliloti 220-5. Ph.D. thesis, Dublin City University

Sabaté DC, Pérez Brandan C, Petroselli G, Erra-Balsells R, Audisio MC (2017) Decrease in the incidence of charcoal root rot in common bean (Phaseolus vulgaris L.) by Bacillus amyloliquefaciens B14, a strain with PGPR properties. Biol Control 113:1-8. https://doi.org/10.1016/j.biocontrol .2017.06.008

Santos S, Neto IFF, Machado MD, Soares HMVM, Soares EV (2014) Siderophore production by Bacillus megaterium: effect of growth phase and cultural conditions. Appl Biochem Biotechnol 172:549-560. https://doi. org/10.1007/s12010-013-0562-y

Schwyn B, Neilands JB (1987) Universal chemical assay for the detection and determination of siderophores. Anal Biochem 160:47-56. https://doi. org/10.1016/0003-2697(87)90612-9

Soutar CD, Stavrinides J (2018) The evolution of three siderophore biosynthetic clusters in environmental and host-associating strains of Pantoea. Mol Genet Genomics 293:1453-1467. https://doi.org/10.1007/s0043 8-018-1477-7

Trifi H, Beb Salem I, Kolsi Benzina N, Fourati A, Costa MC, Achouak W, Sghaier H, Saidi M (2017) Effectiveness of the plant growth-promoting rhizobacterium Pantoea sp. BRM17 in enhancing Brassica napus growth in phosphogypsum-amended soil. Pedosphere 27:1-14. https://doi.org/10.1016/ S1002-0160(17)60454-5

U.S. Department of Health and Human Sevices, Centers for Disease Control, National Institutes of Health (2009) Chosewood LC (eds), Biosafety in microbiological and biomedical laboratories, 5 th edn

Villén M, Lucena JJ, Cartagena MC, Bravo R, García-Mina J, De La Hinojosa MIM (2007) Comparison of two analytical methods for the evaluation of the complexed metal in fertilizers and the complexing capacity of complexing agents. J Agric Food Chem 55:5746-5753. https://doi.org/10.1021/ jf070422t

Yoshida R, Kanno A, Sato T, Kameya T (1996) Cool-temperature-induced chlorosis in rice plants (I. Relationship between the induction and a disturbance of etioplast development). Plant Physiol 110:997-1005. https ://doi.org/10.1104/pp.110.3.997

\section{Publisher's Note}

Springer Nature remains neutral with regard to jurisdictional claims in published maps and institutional affiliations. 